This is a self-archived version of an original article. This version may differ from the original in pagination and typographic details.

Author(s): Sivunen, Anu; Laitinen, Kaisa

Title: Digital communication environments in the workplace

Year: 2020

Version: Accepted version (Final draft)

Copyright: (c) 2020 Taylor \& Francis

Rights: In Copyright

Rights url: http://rightsstatements.org/page/lnC/1.0/?language=en

Please cite the original version:

Sivunen, A., \& Laitinen, K. (2020). Digital communication environments in the workplace. In L. Mikkola, \& M. Valo (Eds.), Workplace Communication (pp. 41-53). Routledge.

https://doi.org/10.4324/9780429196881-4 


\title{
Digital Communication Environments in the Workplace
}

\author{
Anu Sivunen \\ orcid.org/0000-0001-7068-2260
}

Kaisa Laitinen

orcid.org/0000-0001-8357-3020

\begin{abstract}
Digital communication environments consist of various kinds of communication technologies and collaboration platforms. These enable employees to communicate through text, audio, video, and graphics, often in an open and networked way. Complementing the popular standalone communication tools regularly used in workplaces, such as email and instant messaging, digital communication environments enable the sharing, editing, and storing of information publicly within the organization and sometimes externally among its stakeholders. This chapter reviews and analyzes digital communication environments as well as their affordances and constraints for communication and social interaction in the workplace. The chapter considers the issues that need to be discussed and taken into account when digital communication environments are implemented and used in organizations. These environments provide a variety of affordances for task-related communication and effective team performance, and they can support relational communication, foster the creation of new social ties, and strengthen the existing relationships in the workplace. However, questions concerning privacy, surveillance, lack of motivation for use, and reluctance to share information in these environments should also be considered.
\end{abstract}

Keywords: affordances, digital communication environment, platform, communication technology, working life, workplace communication 


\section{DIGITAL COMMUNICATION ENVIRONMENTS IN THE WORKPLACE}

Contemporary working life is becoming increasingly connected, fast-paced, and digital. This is due to the heightened presence of technology in leisure time as well as globalization and advances in technology use in the workplace. First, in everyday life, people are heavily dependent on communication technology, particularly smartphones, both during and outside office hours (Mazmanian, Orlikowski \& Yates 2013). Because people are accustomed to the flexible use of messaging applications and social networking sites on their mobile devices in their leisure time, it is unsurprising that similar types of digital platforms are entering the workplace (see, e.g., Leonardi, Huysman \& Steinfield 2013). Second, because organizations have become more global and geographically distributed, digital communication environments enable employees to collaborate across distinct physical working environments. Moreover, digital communication environments can support distributed work collaborations while employees are travelling or doing mobile work (Hislop \& Axtell 2011) or teleworking from home (Sayah 2013). Thus, digital communication environments play an important role in expanding the limits of the workplace by connecting employees with one another and with work-related content outside traditional workplace boundaries.

Digital communication environments are various types of integrated communication and collaboration platforms at the workplace that enable information transfer and social interaction between employees through text, audio, video, and graphics. These environments enable the sharing, editing, and storing of information among a large number of people in a shared, digital space that can be accessed via different devices, on the go, and often outside organizational firewalls (McAfee 2009). Applications in these environments notify their users when information, messages, or contacts are available, and they support connectivity and awareness between people and between people and information. Thus, digital communication 
environments are important both in smaller workplaces, such as startups where employees are co-located, and in large and complex organizations, such as globally distributed enterprises where these environments are needed for dispersed collaboration (Ellison, Gibbs \& Weber 2015).

Although digital communication environments can provide new communication possibilities for organizational members, the technology-mediated forms of communication can also constrain certain features of social interaction. On one hand, digital communication environments can make communication visible to members across organizational boundaries and increase awareness about who knows what and who knows whom in the organization (Leonardi 2015). These features can facilitate knowledge sharing and organizational learning. On the other hand, digital communication environments can make discussions persistent, meaning that messages remain on the platform after they have been sent and thus become searchable, which may raise questions about surveillance and accountability (Laitinen \& Sivunen 2018; Treem 2015) and weaken employees' willingness to share personal information in these environments. Therefore, the aim of this chapter is to examine the enabling and constraining features of these environments in an in-depth manner, from the perspective of both employees and leaders. Additionally, this chapter provides information about how organizational design logics (Treem, Laitinen \& Sivunen 2019) and developmental goals sometimes conflict with technology users' perceptions and expectations regarding communication in these environments. Finally, various affordances - that is, communication possibilities - of digital communication environments have been identified (Rice et al. 2017; Treem \& Leonardi 2013). Understanding the consequences of these affordances, as well as being aware of their potential constraints, can help organizational members use these environments more effectively in the workplace. 


\section{What Are Digital Communication Environments?}

Digital communication environment is an umbrella term for various types of communication and collaboration platforms. Complementing stand-alone and more closed communication tools regularly used in workplaces, such as email, instant messaging, and traditional intranets, digital communication environments enable the sharing, editing, and storing of information more openly within the organization and sometimes among its stakeholders. Consequently, the information and communication shared in these environments becomes widely visible and searchable within organizational boundaries (McAfee 2009).

Due to their partially open and networked nature, digital working environments are sometimes compared to enterprise 2.0 systems (McAfee 2009) or enterprise social media (ESM) platforms (Leonardi et al. 2013). Here, the broader term "digital communication environments" is used, because these environments often include access to both open discussion forums and information-sharing arenas as well as to more private communities and communication platforms, such as group instant messaging, email, and document sharing and editing tools. Furthermore, digital communication environments often enable the sharing of static content, such as intranet pages updated by organizations' communication departments, and dynamically changing discussion threads created and edited by employees. Thus, digital communication environments include communication and information-sharing possibilities for private interactions with coworkers or in teams as well as for public discussions and content sharing across or sometimes beyond organizational boundaries.

Because digital communication environments can take multiple and often overlapping forms, the implementation and use of such environments require careful consideration of all their possibilities and purposes as well as their limitations, from the perspective of both management and employees. How do the properties of different platforms meet the 
communication needs of the organization and its members? Although technological considerations are essential, it is important to understand the versatile, and sometimes conflicting, perceptions and preferences of the users of these technologies. The way communication technologies are used is heavily shaped by the attitudes, experiences, and expectations of the users (Treem et al. 2015). Because these technologies can hold different meanings for different users, considering employees' perceptions is an important step in the successful utilization of a digital communication environment (Laitinen \& Valo 2018). Understanding the expectations regarding technology and, more importantly, social interaction in the workplace and how workplace communication transitions to these platforms is crucial for the successful implementation and use of digital communication environments.

\section{The Use of Digital Communication Environments for Different Communication} Purposes

Digital communication environments can be used in various ways in the workplace. Due to the expectation that these environments should be easily accessible outside the office and on the go, they are often used via internet browsers. To facilitate easy access, employees' browser settings can be adjusted so that the home page of their internet browser leads them directly to the organization's digital communication environment. Through this web page, employees are able to send email and instant messages, start an audio or video conference with one or several coworkers, find colleagues' contact information, view others' calendars and send meeting invitations, see important organizational news, and read, comment on, and post messages to an organization-wide social network. Furthermore, access to the organization's intranet pages is often possible via the same home page. 
Because of the integrated nature of digital communication environments and their versatile possibilities, it can be challenging for employees to perceive these environments as a single, coherent platform instead of as several different communication tools or to understand the logic underlying how the various parts of the platform should be used (Barbour, Gill \& Barge 2018; Treem et al. 2019). Thus, it is important to collectively discuss how these environments should be used, identify the leaders' and employees' expectations regarding the use of digital communication environments, and determine how employees can best utilize them.

Digital communication environments support three types of organizational communication: (1) one-on-one interpersonal communication between employees; (2) collaborative groupwork possibilities and tools for team meetings; and (3) organization-wide communication possibilities that inform users about their coworkers' expertise and networks. By unpacking these different forms of workplace communication, employees can make better-informed decisions about what possibilities for social interaction the various parts of a digital communication platform can provide. In this way, employees can also become aware of the potential challenges of using these environments in day-to-day communication.

Interpersonal possibilities in digital communication environments

As the digital nature of work has increased, the possibilities for communicating with coworkers have multiplied. The use of communication technology has become an increasingly integral part of the work, and many interpersonal communication processes are conducted in technology-mediated ways. In digital communication environments, several applications, such as email, instant messaging, shared calendars, and audio or video conferencing, can be used for interpersonal communication between colleagues. Despite the 
broad use of digital tools, the communication processes they enable have given rise to several concerns, such as how to enhance perceived proximity between distant colleagues, negotiate about constant connectivity, and choose the right communication tools for certain communication tasks.

Digital communication environments enable distributed workers to be connected to and feel close to one another despite their geographical separation. However, the technologymediated context requires some unique considerations for perceived proximity to emerge. If sufficient consideration is given to the frequency, depth, and interactivity of technologymediated communication (Wilson, O’Leary, Metiu \& Jett 2008), interpersonal work relationships can develop through this form of communication despite the geographical distance. For example, frequent, in-depth communication can reduce uncertainty and prevent feelings of isolation, and this may enhance distant colleagues' identification and perceived proximity with each other (Wilson et al. 2008). When distributed workers know when colleagues are available and which communication channel to use when contacting each other, when they feel at ease about engaging in communication, and when they have routines and practices for both collaboration and focused individual work, distributed collaboration can thrive. Consequently, distant colleagues may feel psychologically as close or even closer than do colleagues working in the same geographical location (O'Leary, Wilson \& Metiu 2014).

Although digital platforms enable connectedness with and easy accessibility to distant coworkers, they can also create constant interruptions in the form of notifications and messages (Fonner \& Roloff 2012). Thus, constant connectivity and the responsibility to be online throughout and even beyond the workday may become a challenge that needs to be negotiated (Mazmanian et al. 2013). In work relationships, employees may develop responsiveness norms and feel pressure to confirm to those norms in terms of the speed with 
which they respond to messages. Especially in global work, strict deadlines accentuated by time zone differences may lead to higher expectations for responsiveness (Sarker \& Sahay 2004). Thus, dispersed coworkers need to manage the connectivity paradox (Leonardi, Treem \& Jackson 2010): The need to engage in focused individual work is now accompanied by the ability to be constantly connected to remote colleagues via communication technology. The expectations regarding connectivity should be negotiated with leaders and between coworkers, and distant colleagues need to agree on when and how they want to be reached and when it is inappropriate to request connections through the digital communication environment.

Successful utilization of digital communication environments for interpersonal communication requires negotiation about which communication tools and channels (video, audio, synchronous text, or asynchronous text) are appropriate for a given collaboration (Ruppel, Gong \& Tworoger 2013) and for a given set of purposes (Sivunen \& Valo 2010). If the work task requires negotiation, a communication tool that enables synchronous discussion through audio or video channels between several coworkers may be better than a text-based asynchronous tool, such as email. If there is a need to inform a number of employees at the same time and with the same content about a decision, a single mass email to all of them may be better than informing everyone separately, for example via one-on-one instant messaging conversations. The criteria for choosing the right communication tool derive from the following questions: (1) What is the aim of the communication, and what kind of social interaction is it intended to support?; and (2) What is the purpose of the tool, and what is the process or form of communication it is expected to support?

However, rational choice, such as selecting a certain tool because of its properties, may not always be the optimal way to decide on which communication tool to use. Even though email often works for simple messages and more interactive communication channels 
may be effective for more complex discussions, other considerations may be important when selecting the right communication technology. For instance, the advent of new digital communication platforms rarely takes place in a void; rather, they are typically implemented in a workplace with preexisting tools and technologies. When selecting the best new tool, both the existing communication environment and established user habits and experiences should be considered. The mere presence of better functions and features in the new technology does not make the transition easy or lead employees to immediately use the new platform. Employees' emotions, organizational events and culture, and the platform's degree of familiarity can all play a role and, thus, should be considered when selecting the best tool (Laitinen \& Sivunen 2018; Stam \& Stanton 2010).

Another important factor shaping communication technology choice - one that was noted several decades ago - is social influence (Fulk, Steinfield, Schmitz \& Power 1987). From this perspective, the selection of communication technology is heavily based on the communication tools recommended and used by one's coworkers or important collaborators, and this kind of social influence may become the predominant reason for the selection of a certain communication technology. Because interpersonal relationships in digital communication environments are often nested in larger social systems, such as teams or projects, the recommendations offered and examples set by these groups play a role in how communication technology selection and technology-mediated communication unfold in the workplace.

Team and collaborative uses of digital communication environments

Communication tools designed and used for team collaboration often include email, instant messaging, shared calendars, audio and video conferencing, and closed or open online 
communities for posting team-related messages and links. Current knowledge about technology-mediated team collaboration through these tools is somewhat contradictory in terms of employee effectiveness and decision-making. For example, the use of instant messaging tools has been found to be an important "backchannel” in teams' decision-making meetings (Dennis, Rennecker \& Hansen 2010). Team members were able to influence decision-making processes through multiple one-on-one discussions using an instant messaging tool during the team meetings.

On the contrary, even though the increasing intensity of technological multitasking, such as multiple instant messaging discussions taking place simultaneously, can at first enhance users' performance, this benefit can be followed by a collapse in performance due to cognitive information-processing challenges (Reinsch, Turner \& Tinsley 2008). The availability cues that instant messaging systems can provide may, however, speed up information exchange and lead to new forms of collaboration, because team members can easily become aware of who is available at a given point in time (Quan-Haase, Cothrel \& Wellman 2005).

On the relational level, the use of collaborative features of digital communication environments, such as text and audio chat, can enhance team members' feelings of social presence (Sivunen \& Nordbäck 2015). Social presence is a "sense of being with another" in a mediated environment (Biocca, Harms \& Burgoon 2003, 456). Even though the intensity of social presence might fluctuate over the course of a virtual team meeting, team members who use text and audio chat to actively engage in simultaneous discussions are able to display their social presence in different ways. If the audio channel is not working or other team members are talking through it, one team member may simultaneously express their presence and involvement in the discussion by typing comments via text chat (Sivunen \& Nordbäck 2015). 
Similarly, it has been found that relational communication, such as the display of emotions, has an important function in virtual teams (Fineman, Maitlis \& Panteli 2007; Glikson \& Erez 2013). Emotional display in virtual settings can be rich and versatile if the same holds for the team's face-to-face communication. Other factors, such as team history and communication norms, often shape emotional and relational communication more than does the digital nature of the team meetings (Glikson \& Erez 2013).

The current understanding of relational communication in technology-mediated team collaboration should be understood in relation to a decades-long discussion about the relational aspects of technology-mediated communication (see, e.g., Walther 1992). These relational aspects include not only emotional display, but also self-disclosure - that is, coworkers' disclosure of private and personal information - as well as emotional and relational social support. At one point, digital communication tools were criticized for "filtering out" necessary communicative cues, thus constraining human interaction. Accordingly, these tools were deemed suitable only for formal communication - not for supporting the relational dimensions of team interaction (Lebie, Rhoades \& McGrath 1996). It is now known that in virtual teams, communication technology can be framed in a variety of ways by the team members. The technology can be perceived as a representation of work and be seen to enhance workplace practices, but at the same time, communication technology can be perceived as a tool for relational communication and relationship maintenance between team members (Laitinen \& Valo 2018). For example, although a conferencing platform can be used simply as a tool to achieve work-related goals, it can also be a common space in which team members can engage in more personal discussions, a way to come together across workplace boundaries. As in face-to-face communication, both task-related and social dimensions are salient in digital team communication. The way employees frame 
digital communication - that is, the way they perceive the technology and technologymediated communication - shapes the extent to which it is used and for what purposes. Hence, collecting feedback or having group discussions and interviews with employees can lead to more aligned framing of the technologies.

Organization-wide use of digital communication environments

Although platforms designed for teams and groupwork as well as for interpersonal communication are a crucial part of the digital communication environment in the workplace, digital communication platforms also support information sharing and coordination at the organizational level. Organization-wide technologies can be divided into intranets and ESM systems. The features shared by these platforms include the ability of all users to see and comment on the shared information and the ability to store or archive information. In addition, ESM systems provide possibilities for communication within smaller or larger communities, and they enable information sharing across the organization through informal status updates or posts. ESM platforms also facilitate networking among employees, because users can follow or friend each other on the platform.

Intranets can be viewed as information and knowledge management tools; that is, they not only enable a large amount of information to be distributed simultaneously to many people, but they also offer a platform on which employees can generate, store, and integrate their knowledge (Edenius \& Borgerson 2003). However, because these platforms are often centrally managed by information systems departments, communication departments, or human resources departments, administrative processing and production of content may decrease members' active communication on the intranet (Wachter \& Gupta 1997). 
Thus, the use of ESM systems has become increasingly popular in organizations. These platforms are versatile, web-based communication tools that enable different forms of communication and networking within organizations (Leonardi et al. 2013). ESM platforms are essentially social media tools and possess many of the properties of social media sites, but the purpose of ESM is to cater to the needs of a specific organization. Thus, the user base and motivations for use are key differences between public social networking sites and ESM systems (Ellison et al. 2015). Some well-known examples of ESM platforms are Yammer and Workplace by Facebook, but many IT companies also provide their own solutions tailored to the needs and wishes of specific organizations.

ESM systems have been found to possess multiple affordances. The technological affordance perspective (Rice et al. 2017) highlights the relationship between the user and the technology by examining communication technologies in terms of how they are used and what possibilities for action they are perceived to offer, rather than just examining their technical properties. The most commonly mentioned are the affordances of visibility, editability, persistence, and association (Treem \& Leonardi 2013). Visibility means that employees can "make their behaviors, knowledge, preferences, and communication network connections that were once invisible (or at least very hard to see) visible to others in the organization" (Treem \& Leonardi 2013, 150). Editability enables communicators to craft and recraft their messages asynchronously before - and sometimes also after - presenting them. Persistence means that communication stays accessible in the same form after it has been sent or presented. Finally, association can be understood as the ability of employees to link information and people. This can take place in the form of linking an individual to a piece of information, such as through a blog contribution or tagging people to an article, or in the form of linking an individual to another person through a social tie (Treem \& Leonardi 2013). Therefore, ESM platforms allow employees to view and publish information for 
coworkers to see, to obtain information about coworkers and increase employees' awareness of their coworkers, to edit already published content, and to access information long after it was first published.

Thus, ESM platforms offer a wide range of possibilities for workplace communication. ESM can be a shared space for the employees to connect, collaborate, and coordinate when they would otherwise not have a physical space in which to do so (Gibbs et al. 2015). Additionally, the affordances of visibility, persistence, and searchability allow employees to use ESM to share and find information needed in their day-to-day work life (Laitinen \& Sivunen 2018). ESM can be used to share information that needs to reach a vast audience in the workplace and afterwards to be found and accessed anytime and anywhere.

Internal information sharing is an important feature of effectively functioning organizations. Because ESM platforms are designed to be based on collaborative content creation by all members of the organization, employees' information sharing on ESM becomes important. Employees' motivations for information sharing on ESM can be manifold, and they are related to organizational tasks and expectations as well as to technological affordances, such as increased awareness of others (Laitinen \& Sivunen 2018).

However, before sharing information, ESM users tend to consider privacy issues and other concerns, such as the nature of the information. These considerations, which include personal and professional privacy management principles (Petronio 2002), may restrict or strongly shape the content shared on ESM. For instance, because employees can perceive the organization-wide ESM as an open platform visible to all employees, they are likely to be conscious about their privacy management strategies and to carefully control the content they share (Laitinen \& Sivunen 2018). Moreover, responsibilities connected to professional roles lead employees to be careful about what to post to a platform that can both immediately make 
the information widely visible and save the shared information permanently to the archives, to be found and interpreted long after the original posting.

Similarly, instead of embracing the visibility ESM affords, employees may also use the features of ESM platforms to enable strategic invisibility (Gibbs, Rozaidi \& Eisenberg 2013). By setting the availability symbols to "absent" or "offline" even when working online, employees can refrain from sharing their expertise with coworkers or prevent coworkers from contacting or disturbing them. Similarly, technological affordances like connectivity may be perceived as constraining by some employees and in certain situations, such as while teleworking at home (Leonardi et al. 2010).

Finally, as digital communication platforms in the workplace become part of organizational members' daily communication environment, these technologies may play an increasingly important role in blurring employees' work-life boundaries (Mazmanian et al. 2013). ESM platforms can be easily accessed through a smartphone application, and notifications about the most recent updates may encourage users to check them outside office hours. Similarly, public social media platforms (such as Facebook, Twitter, and LinkedIn) are strongly integrated into the current digital communication environment in the workplace. Therefore, the work-life boundaries can become even more blurred because of the overlapping work-related and non-work-related networks on these social media sites (Van Zoonen, Verhoeven \& Vliegenthart 2016). When sharing information in both digital communication environments in the workplace and on public social media, employees need to consider which aspects of their professional and personal identity they want to conceal and which aspects they want to disclose, as well as the consequences these choices may have for their accountability, others' perceptions of their expertise, and their future career opportunities. 


\section{Practical Implications}

Workplace digital communication environments provide many possibilities for interpersonal, group, and organization-level communication. They enable both co-located and distributed employees to share and edit information, express their feelings and emotions, get to know one another, and store important information in a digital space that can easily be accessed from various locations and with various devices.

However, these environments raise questions and concerns regarding the responsibilities associated with finding and sharing important information, the significance of communicating in these environments for employees' accountability, expertise, and helping behaviors, and how employees manage their impressions, privacy, and work-life boundaries. Both leaders and employees need to consider several critical aspects when digital communication environments are implemented and used. These aspects are connected to technological affordances, the design logics of the platform, the communication needs at work, and the perceptions and expectations of leaders and employees. Thus, giving time and attention to these considerations is important both when (re)considering the current use of digital communication environments and when aiming to successfully implement new digital platforms in the workplace.

\section{What to Consider in the Workplace:}

- Access to the digital communication environment. The ways in which the digital communication environment can be accessed shape the ways it is used. If the environment is accessible from outside organizational firewalls or without virtual private network (VPN) connections, logging in to the environment is often easier and faster. Being able to access the environment with a smartphone is also easier on the 
go. However, easy access may also intensify the blurring of boundaries between work and other life domains.

- Collaboration possibilities. It is important to consider what type of collaboration possibilities the digital communication environment provides for colleagues within and outside one's team or unit. Is it possible to use text, audio, and video channels for collaboration, sharing screens, or editing documents? Are all these channels used efficiently and appropriately?

- Control and management of the digital communication environment. While using the platform, employees should consider the options for managing their privacy and availability on the platform. Employees should be aware of their privacy settings and who can see the content they share. It would also be important to discuss when employees should be available on the platform and to identify their preferred method of contact.

- External collaboration possibilities. When employees are using the digital communication environment, it may be important that external partners or stakeholders can access certain tools of the platform. Therefore, the collaboration possibilities across organizational boundaries provided by the digital communication environment should be considered.

- Meanings given to the digital communication environment. It is important to be aware of the attitudes and expectations regarding the digital communication environment. How do employees and leaders perceive the environment, and are these perceptions aligned?

- Sharing and storing information. When using digital communication environments in the workplace, the ways of and possibilities for sharing and storing information 
become an important issue. All employees should be able to ensure that they share information with the right people and store it in the right places.

- The design logic of the digital communication environment. Depending on whether the platform is a self-service environment where employees can easily find relevant (static) information, or whether it is a collaborative and dynamic platform, the logic of use is vastly different. Therefore, this logic needs to be considered when planning the use of digital communication environments.

- Visibility in the digital communication environment. Some of the benefits of the digital communication environment are related to the ability of employees to be aware of other users and of content to which they are not directly connected themselves. Therefore, employees should consider their own visibility in the digital communication environment. Are there ways to signal one's expertise and knowledge to others (such as profile pages)? Are the possibilities for self-presentation and learning from others' expertise fully utilized?

\section{References}

Barbour, J. B., Gill, R. \& Barge, J. K. 2018. Organizational communication design logics: A theory of communicative intervention and collective communication design. Communication Theory 28, 332-353.

Biocca, F., Harms, C. \& Burgoon, J. K. 2003. Toward a more robust theory and measure of social presence: Review and suggested criteria. Presence: Teleoperators and Virtual Environments, 12, 456-480. 
Dennis, A. R., Rennecker, J. A. \& Hansen, S. 2010. Invisible whispering: Restructuring collaborative decision making with instant messaging. Decision Sciences 41 (4), 845-886.

Edenius, M. \& Borgerson, J. 2003. To manage knowledge by intranet. Journal of Knowledge Management 7 (5), 124-136.

Ellison, N. B, Gibbs, J. L. \& Weber, M. S. 2015. The use of enterprise social network sites for knowledge sharing in distributed organizations: The role of organizational affordances. American Behavioral Scientist 59 (1), 103-123.

Fineman, S., Maitlis, S. \& Panteli, N. 2007. Virtuality and emotion. Human Relations 60 (4), $555-560$.

Fonner, K. L. \& Roloff, M. E. 2012. Testing the connectivity paradox: Linking teleworkers' communication media use to social presence, stress from interruptions, and organizational identification. Communication Monographs 79 (2), 205-231.

Fulk, J., Steinfield, C. W., Schmitz, J. \& Power, J. G. 1987. A social information processing model of media use in organizations. Communication Research 14 (5), 529-552.

Gibbs, J. L., Eisenberg, J., Rozaidi, N. A. \& Gryaznova, A. 2015. The "Megapozitiv" role of enterprise social media in enabling cross-boundary communication in a distributed Russian organization. American Behavioral Scientist 59 (1), 75-102. 
Gibbs, J. L., Rozaidi, N. A. \& Eisenberg, J. 2013. Overcoming the "ideology of openness": Probing the affordances of social media for organizational knowledge sharing. Journal of Computer-Mediated Communication 19 (1), 102-120.

Glikson, E. \& Erez, M. 2013. Emotion display norms in virtual teams. Journal of Personnel Psychology 12 (1), 22-32.

Hislop, D. \& Axtell, C. 2011. Mobile phones during work and non-work time: A case study of mobile, non-managerial workers. Information and Organization 21(1), 41-56.

Laitinen, K. \& Sivunen, A. 2018. Privacy principles and technological affordances shaping employees' information sharing in enterprise social media. Paper presented at the 68 th International Communication Association Conference, Prague, Czech Republic, May 24-28.

Laitinen, K. \& Valo, M. 2018. Meanings of communication technology in virtual team meetings: Framing technology-related interaction. International Journal of Human-Computer Studies 111, 12-22.

Lebie, L., Rhoades, J. \& McGrath, J. 1996. Interaction process in computer-mediated and face-to-face groups. Computer Supported Cooperative Work 4, 127-152.

Leonardi, P. M. (2015). Ambient awareness and knowledge acquisition: Using social media to learn "who knows what" and "who knows whom.” MIS Quarterly 39 (4), 747-762. 
Leonardi, P. M., Huysman, M. \& Steinfield, C. 2013. Enterprise social media: Definition, history, and prospects for the study of social technologies in organizations. Journal of Computer-Mediated Communication 19 (1), 1-19.

Leonardi, P. M., Treem, J. W. \& Jackson, M. H. 2010. The connectivity paradox: Using technology to both decrease and increase perceptions of distance in distributed work arrangements. Journal of Applied Communication Research 38 (1), 85-105.

Mazmanian, M., Orlikowski, W. J. \& Yates, J. 2013. The autonomy paradox: The implications of mobile email devices for knowledge professionals. Organization Science 24 (5), 1337-1357.

McAfee, A. 2009. Enterprise 2.0: New collaborative tools for your organization's toughest challenges. Boston, MA: Harvard Business Press.

O'Leary, M. B., Wilson, J. M. \& Metiu, A. 2014. Beyond being there: The symbolic role of communication and identification in perceptions of proximity to geographically dispersed colleagues. MIS Quarterly 38 (4), 1219-1243.

Petronio, S. 2002. Boundaries of privacy: Dialectics of disclosure. Albany, NY: SUNY Press.

Quan-Haase, A., Cothrel, J. \& Wellman, B. 2005. Instant messaging for collaboration: A case study of a high-tech firm. Journal of Computer-Mediated Communication 10 (4). https://doi.org/10.1111/j.1083-6101.2005.tb00276.x 
Reinsch Jr., N. L., Turner, J. W. \& Tinsley, C. H. 2008. Multicommunicating: A practice whose time has come? Academy of Management Review 33 (2), 391-403.

Rice, R. E., Evans, S. K., Pearce, K. E., Sivunen, A., Vitak, J. \& Treem, J. W. 2017. Organizational media affordances: Operationalization and associations with media use. Journal of Communication 67 (1), 106-130.

Ruppel, C. P., Gong, B. \& Tworoger, L. C. 2013. Using communication choices as a boundary-management strategy: How choices of communication media affect the work-life balance of teleworkers in a global virtual team. Journal of Business and Technical Communication 27 (4), 436-471.

Sarker, S. \& Sahay, S. 2004. Implications of space and time for distributed work: An interpretive study of US-Norwegian systems development teams. European Journal of Information Systems 13 (1), 3-20.

Sayah, S. 2013. Managing work-life boundaries with information and communication technologies: The case of independent contractors. New Technology, Work and Employment 28 (3), 179-196.

Sivunen, A. \& Nordbäck, E. 2015. Social presence as a multi-dimensional group construct in 3D virtual environments. Journal of Computer-Mediated Communication 20 (1), 19-36. 
Sivunen, A. \& Valo, M. 2010. Communication technologies. In R. Ubell (Ed) Virtual teamwork: Mastering the art and practice of online learning and corporate collaboration. Hoboken, NJ: John Wiley \& Sons, 137-157.

Stam, K. R., Stanton, J. M. 2010. Events, emotions, and technology: examining acceptance of workplace technology changes. Information Technology \& People, 23 (1), $23-53$.

Treem, J. W. 2015. Social media as technologies of accountability: Explaining resistance to implementation within organizations. American Behavioral Scientist 59 (1), 53-74.

Treem, J. W., Dailey, S. L., Pierce, C. S. \& Leonardi, P. M. 2015. Bringing technological frames to work: How previous experience with social media shapes the technology's meaning in an organization. Journal of Communication 65, 396-422.

Treem, J. W., Laitinen, K. \& Sivunen, A. 2019. Can you have a social intranet? Examining multiple design logics in the implementation of information and communication technologies in organizations. Paper presented at the 69th Annual International Communication Association Conference, Washington, D.C., USA, May 24-28.

Treem, J. W. \& Leonardi, P. M. 2013. Social media use in organizations: Exploring the affordances of visibility, editability, persistence, and association. Annals of the International Communication Association 36 (1), 143-189.

Van Zoonen, W., Verhoeven, J. W. \& Vliegenthart, R. 2016. Social media's dark side: Inducing boundary conflicts. Journal of Managerial Psychology 31 (8), 1297-1311. 
Wachter, R. M. \& Gupta, J. N. 1997. The establishment and management of corporate intranets. International Journal of Information Management 17 (6), 393-404.

Walther, J. B, 1992. Interpersonal effects in computer-mediated interaction: A relational perspective. Communication Research 19 (1), 52-90.

Wilson, J. M., Boyer O'Leary, M., Metiu, A. \& Jett, Q. R. 2008. Perceived proximity in virtual work: Explaining the paradox of far-but-close. Organization studies 29 (7), 979-1002. 